\title{
Stage IIIA Ovarian Cancer AJCC v8
}

National Cancer Institute

\section{Source}

National Cancer Institute. Stage IIIA Ovarian Cancer A/CC v8. NCI Thesaurus. Code C139972.

Stage IIIA includes: IIIA1: T1/2, N1, M0; IIIA2: T3a, NO/N1, M0. T1: Ovarian cancer with tumor limited to ovaries (one or both). T2: Ovarian cancer with tumor involving one or both ovaries with pelvic extension below pelvic brim. T3a: Ovarian cancer with microscopic extrapelvic (above the pelvic brim) peritoneal involvement with or without positive retroperitoneal lymph nodes. N0: No regional lymph node metastasis. N1: Positive retroperitoneal lymph nodes only (histologically confirmed). M0: No distant metastasis. (AJCC 8th Ed.) 